\title{
ASSESSMENT OF COMPRESSIVE STRENGTH OF HISTORIC MIXED MASONRY
}

\author{
Jiří WITZANY', Tomáš ČEJKA ${ }^{\mathrm{a}}$, Miroslav SÝKORA ${ }^{\mathrm{b}}$, Milan HOLICKÝ ${ }^{\mathrm{b}}$ \\ ${ }^{a}$ Department of Building Structures, Faculty of Civil Engineering, Czech Technical University in Prague, \\ Thákurova 7, 16629 Prague, Czech Republic \\ ${ }^{b}$ Klokner Institute, Czech Technical University in Prague, Šolinova 7, 16608 Prague, Czech Republic
}

Received 12 Apr 2013; accepted 08 Jan 2014

\begin{abstract}
The majority of load-bearing masonry structures of historic buildings are built of mixed or stone masonry composed of regular or irregular (so-called quarry) masonry units - bricks, sedimentary and metamorphic rock - possessing often very different physical and mechanical characteristics. The identification of residual mechanical properties of stone or mixed masonry of irregular walling units requires the application of a suitable diagnostic method, the assessment of the phase of degradation processes and the choice of an appropriate probabilistic model for the strength of mixed masonry. The presented experimental research involves the analysis of the heterogeneity (homogeneity) of mixed masonry of a church from the $17^{\text {th }}$ century. The probabilistic model for masonry strength is developed on the basis of destructive and non-destructive testing of masonry units and mortar. It appears that the probabilistic approach leads to a design value by $75 \%$ higher than the deterministic approach.
\end{abstract}

Keywords: mixed masonry, stone masonry, destructive test, non-destructive test, probabilistic model, masonry strength.

\section{Introduction}

Due to their great variability, material properties of historic masonry are, as a rule, assessed on the basis of tests. The evaluation of masonry strength is then a key task in the reliability assessment of a structure. In particular, the assessment of mixed masonry poses an extreme difficulty. The failure mechanism of mixed masonry composed of irregular masonry units differs from the failure mechanism of coursed masonry of regular masonry units. The failure mechanism of masonry loaded in concentric compression and the exhaustion of its load-bearing capacity in compression are characterised by the appearance and development of vertical, mainly tensile cracks. The first cracks arise at the points of a masonry structure where the acting tensile normal stress $\sigma_{\mathrm{x}}$ (principal stress $\sigma_{1}$ ) exceeds the local tensile strength of masonry, or where the transverse deformation exceeds the ultimate relative tensile strain (Witzany et al. 2008; Winkler 1975).

Due to this mechanism, the compressive strength of masonry relies not only on the compressive strength of masonry units, the compressive strength of mortar, but also on the tensile strength of masonry units, or the tensile strength of $\operatorname{mortar} f_{m t}$ (Kotlík et al. 1999; Šatava 1973). The tensile strength of masonry units contributes when loading approaches the ultimate strength of masonry, i.e. after crack development and in the case of masonry with low quality mortar. Due to the interaction between mortar and masonry units (Fig. 1), spatial stress state arises in the masonry (Witzany et al. 2006, 2008).

The above mechanism of the mutual interaction of masonry units and connecting mortar, as a rule, only applies at a certain level of compressive strain of masonry, in common cases under loads below $60 \%$ of the ultimate load (Witzany et al. 2009).

The favourable effect of a higher strength and modulus of elasticity of masonry units as compared to the filler in the joints (as in the case of coursed masonry composed of regular walling units) does not apply in masonry composed of irregular quarry stone. A relatively complex stress state occurs in the vicinity of irregular masonry units, mainly sharp edges, characterised by the appearance of local, frequently extreme values of normal and shear stresses preceding the development of cracks.

Experimental tests of stone piers of regular sandstone blocks and of quarry sandstone pointed out the serious effect of irregular masonry of quarry stone on its load-bearing capacity (Fig. 2). The predominantly positive effect of the triaxial compressive stress state of mortar in classic brickwork cannot be applied to stone or mixed masonry with chippings, sharp-edged walling units of freestone, irregular bed and butt joints.

Corresponding author: Tomáš Čejka

E-mail: cejka@fsv.cvut.cz 

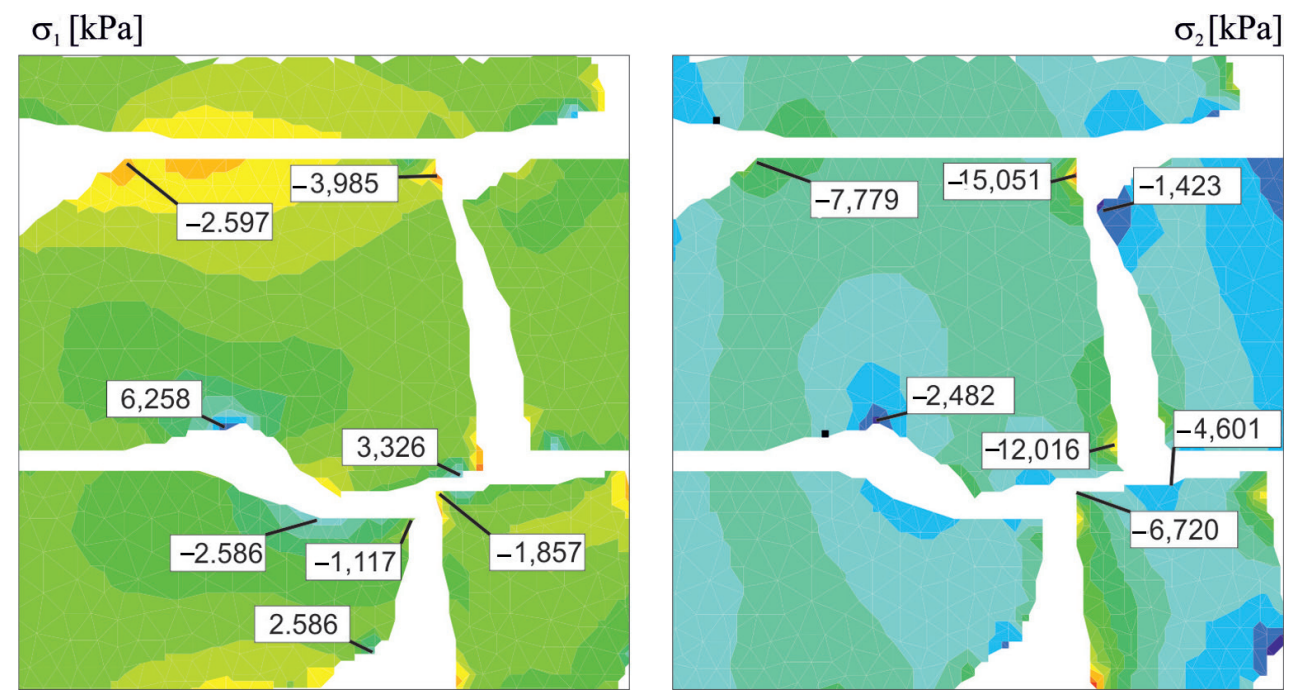

Fig. 1. Local stress concentrations around the edges of masonry units (modulus of elasticity of mortar $E_{\mathrm{m}}=1000 \mathrm{MPa}$, modulus of elasticity of sandstone $E_{\mathrm{p}}=10000 \mathrm{MPa}$; principal stresses in mortar are not plotted for better clarity)

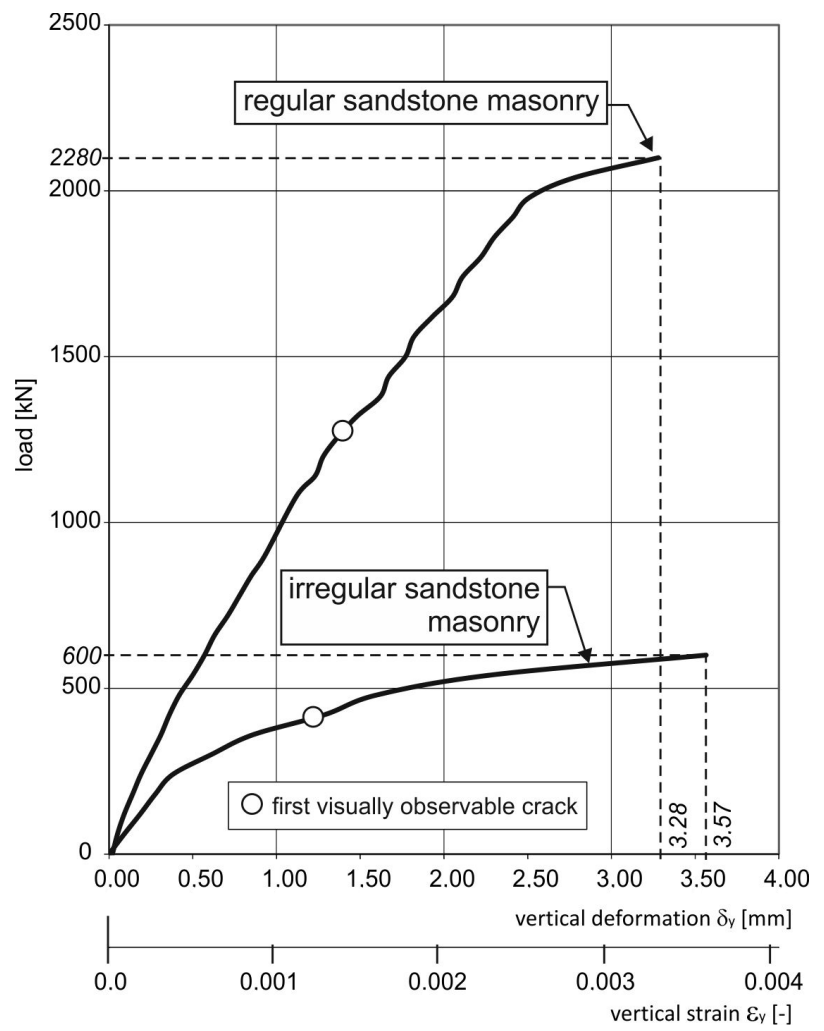

Fig. 2. Experimentally identified working diagrams of sandstone masonry of regular blocks and of quarry stone

\section{Experimental research of historic mixed masonry}

Experimental research of the strength of masonry units and mortar was performed in the cross sections of a virtual network "laid" onto an investigated section of mixed masonry of a church from the $17^{\text {th }}$ century (Fig. 3). The virtual network with dimensions of $9 \times 4 \mathrm{~m}$ was "laid" onto the investigated wall of mixed masonry. The intersections of this virtual network (the total of 18 intersections, Table 1) were the points for the destructive and non-destructive testing of masonry units and mortar.

The values of standardised compressive strength of bricks, or sandstone, obtained by a destructive test on test cores with a diameter of $35 \mathrm{~mm}$ and a length of about $50-70 \mathrm{~mm}$ at points of the virtual network intersections serve as the basis for the comparison with the values obtained by non-destructive methods.

Compressive strengths obtained by destructive tests may be slightly conservative since local damage might be caused by drilling and undetected by visual check of cores before testing. In the considered case this effect is deemed relevant particularly for the bricks. However, uncertainties related to this phenomenon are neglected hereafter as they are much lower compared to these related to the non-destructive techniques.

The compressive strengths obtained by test cores in a press show a non-uniform distribution of the characteristics of mixed masonry (Fig. 4). Compressive strengths of bricks range from 58 to $192 \%$ around the mean obtained for both materials; or in the interval from 17 to $137 \%$ in the case of sandstone.

The sampling of test cores cooled by water requires the identification of the moisture content of walling units at the site of presumed sampling (before sampling) and a subsequent modification of the moisture content of a sampled specimen to the level corresponding to the initial masonry moisture at the site of the sampled specimen.

The water content ( $\%$ mass) of masonry at the points of individual samplings ranged from $0.1 \%$ to $14.38 \%$. Figures 5 and 6 show the distribution of water content (\% mass) and compressive strength of masonry units (bricks) and mortar in the intersections of the virtual network.

Figure 7 displaying the contents of selected salts detected by laboratory testing of sandstone specimens shows the drop in the compressive strength of sandstone with the growth of salt contents in the pore system. 


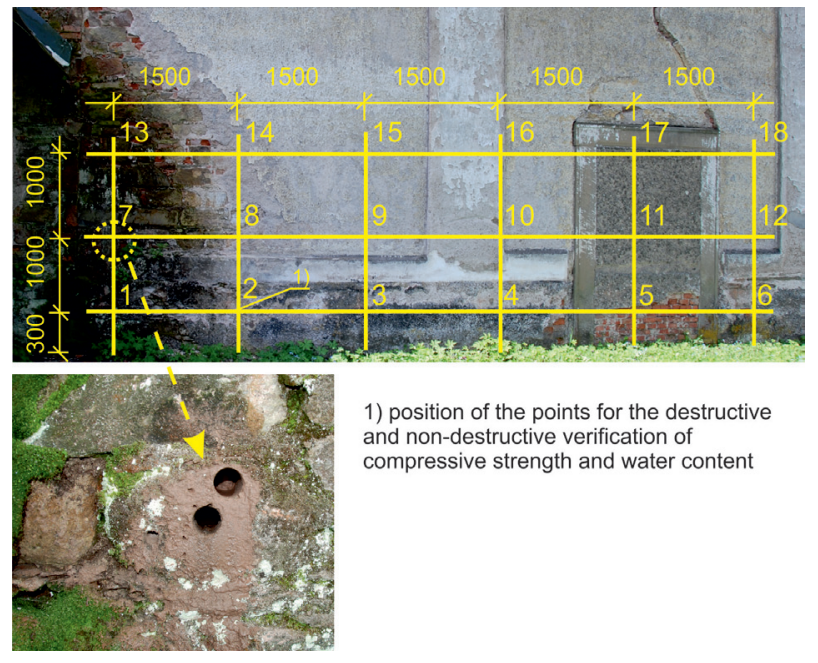

Fig. 3. An example of an investigated masonry structure with a marked virtual network - a wall of the church from the $17^{\text {th }}$ century in Fořt, Czech Republic

Table 1. Strengths of sandstone, bricks and mortar [MPa]

\begin{tabular}{|c|c|c|c|c|}
\hline \multirow{2}{*}{ Location } & \multicolumn{3}{|c|}{ Masonry units } & \multirow{2}{*}{$\frac{\text { Mortar }}{\text { Drill }}$} \\
\hline & Press & Schmidt & Drill & \\
\hline 1 & 5.0 & 30.4 & 16.8 & 1.66 \\
\hline 2 & 24.9 & 16.1 & 38.9 & 2 \\
\hline 3 & 22.6 & 27.0 & 28.4 & 1.53 \\
\hline 4 & 24.6 & 24.3 & 29.9 & 1.04 \\
\hline $5^{*}$ & 7.6 & 20.9 & 21.3 & 1.34 \\
\hline 6 & 24.5 & 21.9 & 26.9 & 1.1 \\
\hline 7 & 32.5 & 33.5 & 35.4 & 1.89 \\
\hline 8 & 38.2 & 30.9 & 34.5 & 1.5 \\
\hline 9 & 32.6 & 30.3 & 39.0 & 1.8 \\
\hline 10 & 35.9 & 31.4 & 34.4 & 1.23 \\
\hline $11^{*}$ & 11.2 & 30.3 & 35.5 & $\mathrm{X}$ \\
\hline 12 & 37.8 & 29.1 & 36.3 & 1.21 \\
\hline $13 *$ & 4.3 & 10.2 & 1.0 & 1.41 \\
\hline $14 *$ & 6.3 & 17.4 & 11.4 & 1.38 \\
\hline 15 & 33.1 & 25.5 & 38.2 & 1.12 \\
\hline 16 & 40.2 & 27.2 & 35.7 & 1.72 \\
\hline 17 & 40.2 & 21.7 & 34.4 & 1.45 \\
\hline $18 *$ & 9.2 & 20.6 & 19.0 & 1.1 \\
\hline
\end{tabular}

Legend: *bricks (sandstone otherwise), X - not measured, strength of mortar obtained only drill, low strength of brick obtained by a press could be considered with regard of size of test cores.

Figure 8 indicates that the compressive strengths of bricks obtained by a modified percussion drill with an indenter range from 272 to $289 \%$ as compared to those obtained by a press (100\%). With the Schmidt hardness tester, the differences range from 232 to $259 \%$. For sandstone masonry, the compressive strengths obtained by the drill vary from 97 to $427 \%$; for the Schmidt hammer, the strengths range from 83 to $302 \%$. mixed masonry

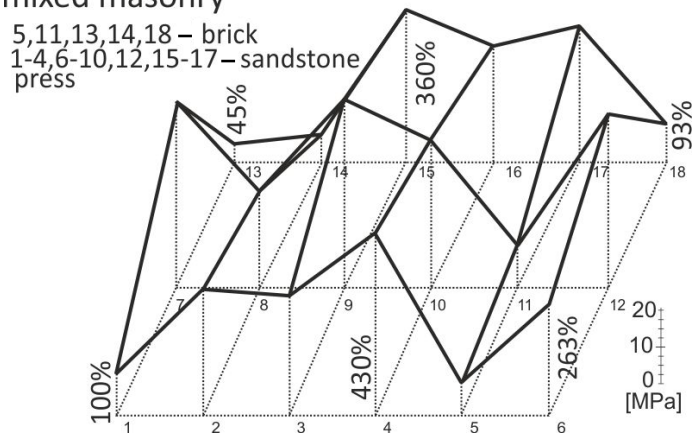

Fig. 4. Comparison of compressive strengths of masonry units obtained by a press (reference value $(100 \%)$ is the strength in the point \#1)
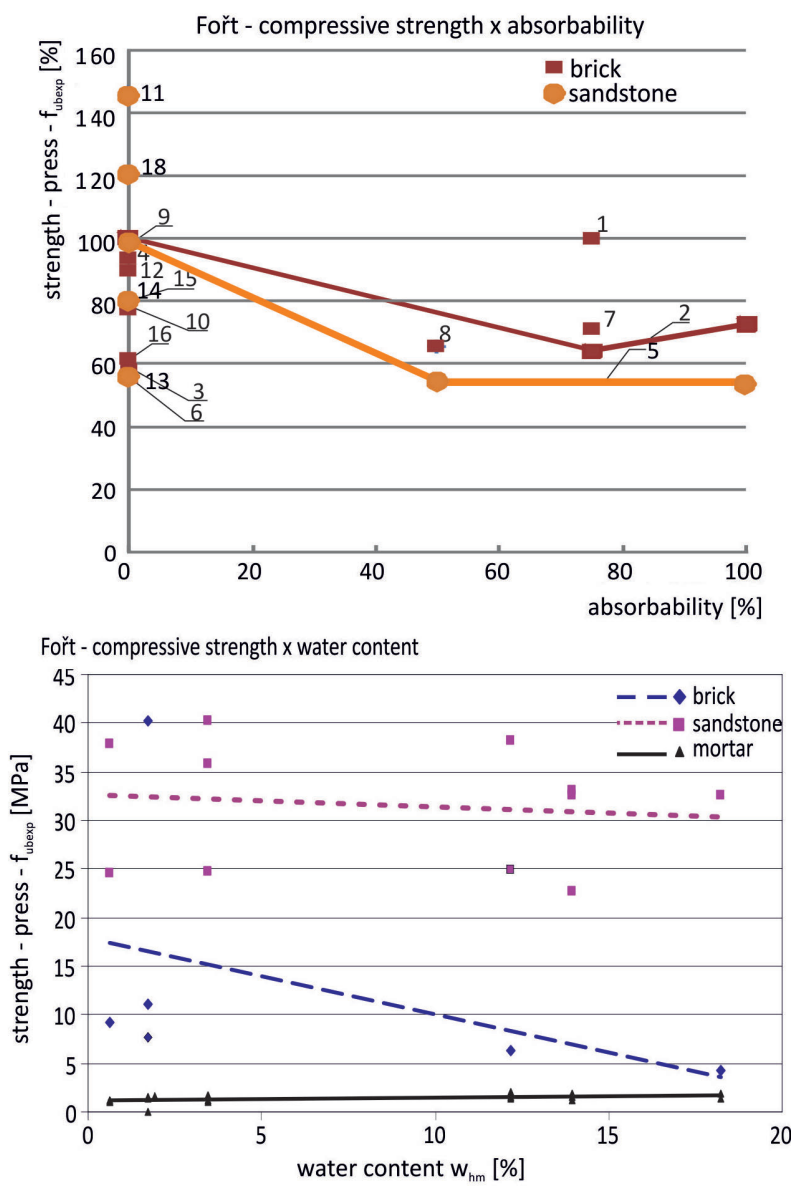

Fig. 5. Experimentally obtained relationships of compressive strength $f_{\mathrm{u} \text {,exp }}$ and water content $w_{\mathrm{hm}}$ for bricks and sandstone

\section{Assessment of compressive strengths of bricks and sandstone masonry units}

\subsection{Destructive tests}

Based on long-term experience, the strengths of masonry units in a press are considered more credible than those obtained by the Schmidt hammer and a drill. The data from a press are, therefore, considered as initial whereas the results obtained by non-destructive techniques are informative only. 


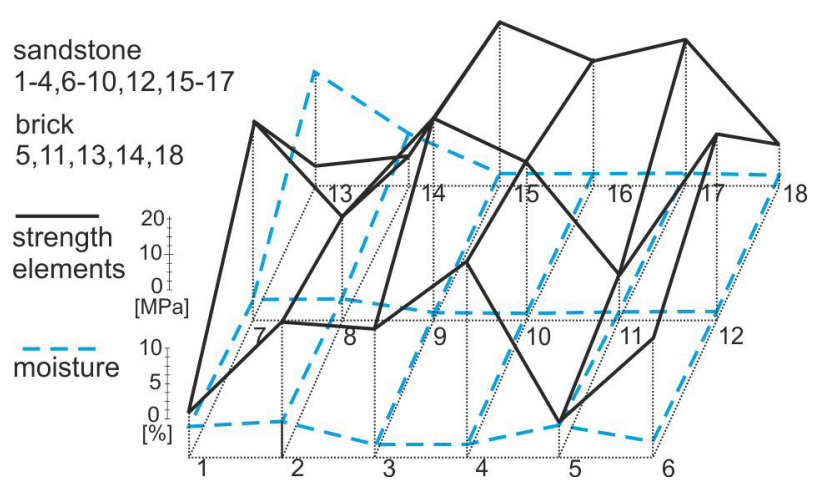

Fig. 6. The distribution of the water content and compressive strength of masonry units (bricks, sandstone)

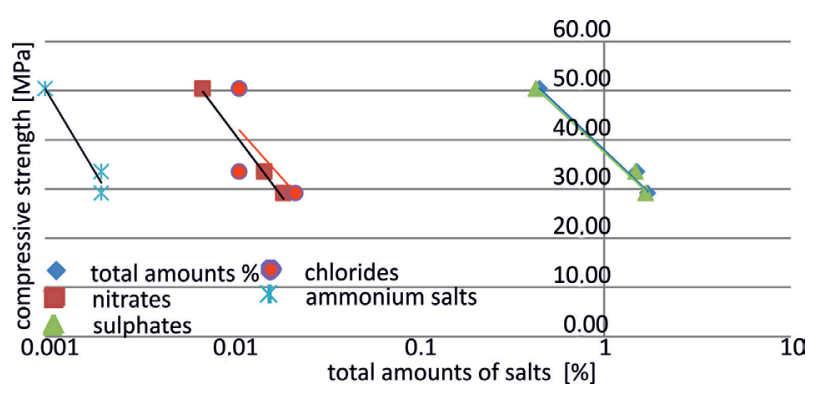

Fig. 7. The effect of the content of selected salts on the compressive strength of sandstone

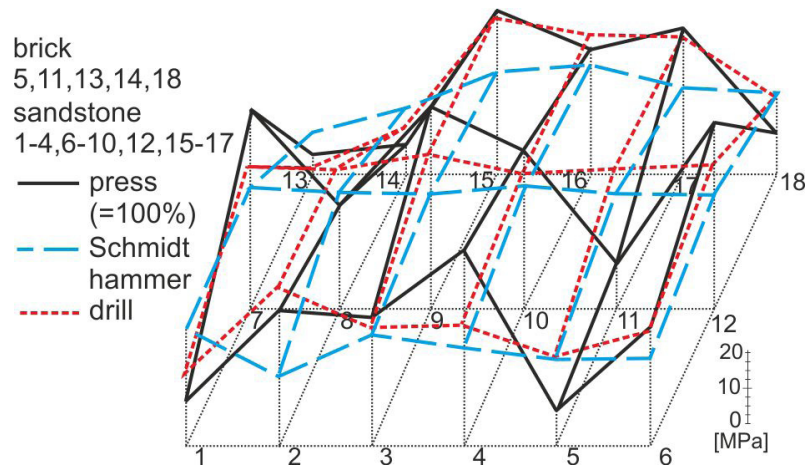

Fig. 8. The comparison of compressive strengths of masonry units obtained by non-destructive methods with those obtained by a press $(100 \%=$ strength by a press $)$

Two alternatives of the analysis are considered:

- alt. A: masonry strength is dominated by the material with lower strength (bricks),

- alt. B: masonry strength is affected by both "randomly mixed" materials.

Alt. A can be relevant e.g. for columns between openings or supports of vaults or arches where loads are concentrated. In other cases (such as walls without openings) alt. B can be considered.

It is verified whether the samples (Table 1) include outliers that may arise by a measurement error or by measurement at a point of a local non-homogeneity. Outliers may distort the assessment results, which, in turn, may lead to erroneous conclusions. Grubbs' test for outliers
(Grubbs 1969; Ang, Tang 2007; Holický 2013) indicates that the hypothesis that a data set contains outliers can be rejected (for both alt. A and B). A significance level of 0.05 (a common value for engineering applications, Holický 2013) is accepted.

Legend: *bricks (sandstone otherwise), X - not measured, strength of mortar obtained only drill, low strength of brick obtained by a press could be considered with regard of size of test cores.

Sample characteristics of the tests in a press using the method of moments (Ang, Tang 2007; Holický 2013) are summarised in Table 2. The histogram for alt. B in Figure 9 clearly indicates the combination of two materials with different strengths and a large scatter of data.

When assessing the mean value (needed to estimate masonry strength as discussed below) the statistical uncertainty resulting from a limited sample size should be considered. The interval of the mean $\mu$ of a variable with a normal distribution and unknown standard deviation (obtained by measurements) is estimated as (Ang, Tang 2007; Holický 2013):

$$
\begin{aligned}
& \mathrm{m}+\mathrm{t}(1-\gamma) / 2(\mathrm{n}-1) \mathrm{s} / \sqrt{\mathrm{n}}<\mu< \\
& \mathrm{m}+\mathrm{t}(1+\gamma) / 2(\mathrm{n}-1) \mathrm{s} / \sqrt{\mathrm{n}},
\end{aligned}
$$

where: $n$ denotes the sample size - the number of measurements $x_{i}(i=1, \ldots, n), m=\sum_{\mathrm{i}} x_{\mathrm{i}} / n$ the sample mean, $s=\sqrt{ }\left[\sum_{\mathrm{i}}\left(x_{\mathrm{i}}-m\right)^{2}\right] /(n-1)$ the sample standard deviation, $t_{\mathrm{p}}(n-1)$ the fractile of the Student's $t$ distribution corresponding to the probability $p$ and $(n-1)$ degrees of freedom, and $\gamma$ is a selected confidence, i.e. the probability that an estimated interval covers the mean value. Considering $\gamma=0.75$ (a common value for civil engineering applications, ISO 2394:1998 (1998)), Eqn (1) leads to:

$$
\begin{gathered}
\text { alt. A: } 5.9 \mathrm{MPa}<\mu_{f b \text {,est }}<9.5 \mathrm{MPa} \\
\text { alt. } B: 20.1 \mathrm{MPa}<\mu_{f b \text {,est }}<27.8 \mathrm{MPa} .
\end{gathered}
$$

It is evident that statistical uncertainties need to be taken into account in both alternatives. The lower bound is smaller than the sample mean (Table 2) by about $25 \%$ as

Table 2. Statistical characteristics of variables affecting masonry strength

\begin{tabular}{lccc}
\hline \multicolumn{1}{c}{ Variable } & Symbol & $\mu$ & $V$ \\
\hline $\begin{array}{l}\text { Masonry units strength } \\
(\text { alt. } A)\end{array}$ & $f_{\mathrm{b}, \text { test }(\mathrm{A})}$ & $7.7 \mathrm{MPa}$ & 0.34 \\
\hline $\begin{array}{l}\text { Masonry units strength } \\
(\text { alt. } B)\end{array}$ & $f_{\mathrm{b}, \text { test }(\mathrm{B})}$ & $23.9 \mathrm{MPa}$ & 0.56 \\
\hline Conversion factor - units & $\eta_{\mathrm{b}}$ & 1 & 0.2 \\
\hline Mortar strength & $f_{\mathrm{m}, \mathrm{test}}$ & $1.44 \mathrm{MPa}$ & 0.2 \\
\hline Conversion factor - mortar & $\eta_{\mathrm{m}}$ & 1 & 0.2 \\
\hline $\begin{array}{l}\text { Coefficient for calculation } \\
\text { of } f\end{array}$ & $K$ & $\sim 1.25 K_{\mathrm{nom}}$ & 0.2 \\
\hline
\end{tabular}




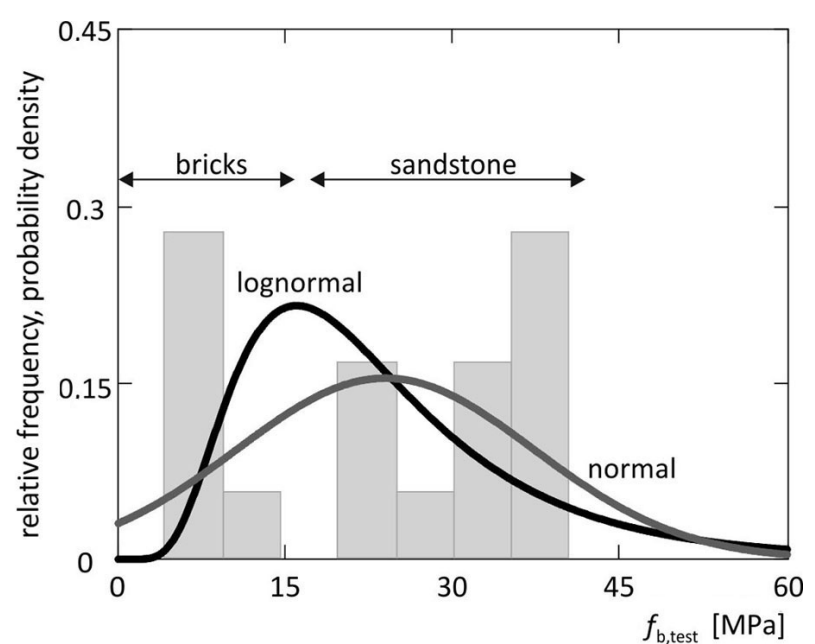

Fig. 9. Histogram of the strength of masonry units obtained by a press and fitted lognormal and normal distributions (alt. B)

a consequence of the low sample size in alt. A $(n=5)$. The difference of $15 \%$ due to a high coefficient of variation $(v=0.56)$ then results from the combination of the two materials in alt. B.

A lognormal distribution with the origin at zero (hereafter "lognormal distribution") is commonly an appropriate model for the strength of masonry units. Using the sample characteristics in Table 2, the probability density functions of a lognormal and normal distribution (another often suitable theoretical model) are shown in Figure 9.

\subsection{Non-destructive tests - Schmidt hammer (type L)}

Figure 10 presents the strengths of masonry units obtained by the Schmidt hammer and a press for alt. B. Using linear regression analysis (Ang, Tang 2007; Holický 2013), the relationship of the strengths obtained by a press and by the Schmidt hammer and the prediction interval for a $75 \%$ confidence are plotted in grey. The relationship is deemed weak to moderate as also confirmed by a relatively low correlation coefficient of 0.5 . The prediction interval is considerably wide and of low relevance for practical applications. The credibility of measurements with the Schmidt hammer thus seems spurious in this case.

\subsection{Non-destructive tests - drill with an indenter}

Figure 10 presents the strengths of masonry units obtained by the drill, and the trend and the prediction interval indicated by the black curves. Apparently, the strength of masonry units is estimated slightly better by the drill than by the Schmidt hammer. The correlation coefficient of 0.8 shows a strong statistical dependence between the strengths obtained by a press and the drill. Despite this, the prediction interval is still wide. For example, when $35 \mathrm{MPa}$ is estimated by the drill, the strength in a press ranges from 20 to $40 \mathrm{MPa}$ with $75 \%$ probability. Hence, the credibility of the results obtained by the drill is again low. It is thus recommended to exploit the results obtained by the drill (or by the Schmidt hammer) for

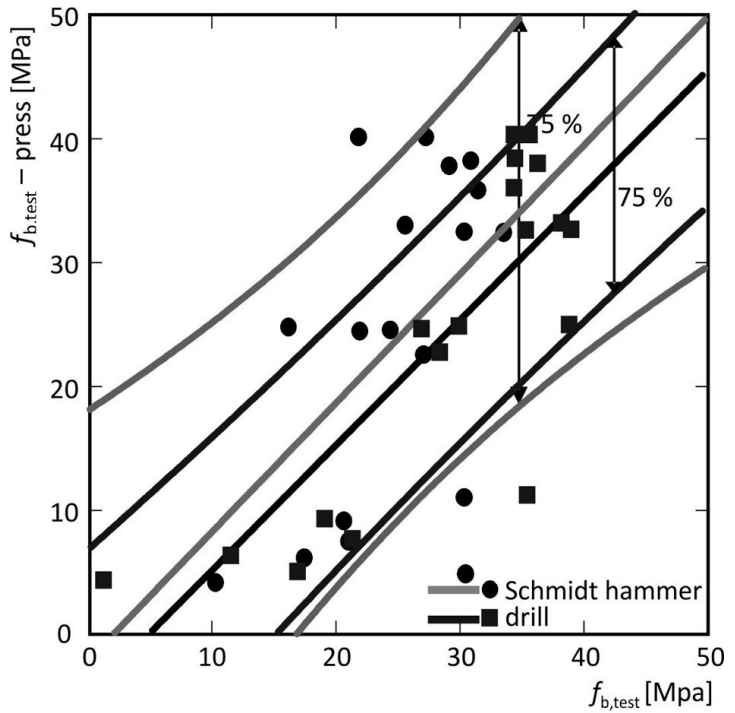

Fig. 10. Strengths of masonry units obtained by the Schmidt hammer or the drill and a press

the identification of erroneous measurements in a press rather than for the strength assessment.

\section{Assessment of compressive strength of mortar}

Grubbs' test detects no outlying observations in the sample of mortar strengths (obtained by the drill, Table 1). Statistical characteristics are indicated in Table 2; Eqn (1) leads to:

$$
1.35 \mathrm{MPa}<\mu_{\text {fm,test }}<1.53 \mathrm{MPa} .
$$

In the case of mortar, statistical uncertainties are less significant - the lower bound is smaller than the sample mean by about $7 \%$. A lognormal distribution is an appropriate probabilistic model.

\section{Evaluation of masonry strength}

It has been recognised that the partial factor method tends to be conservative in the assessment of existing structures. This may lead to costly repairs and losses of the heritage value in the case of historic structures (Stewart, Lawrence 2002, 2007; Mojsilovic, Faber 2009; Holický et al. 2009; Sykora, Holicky 2010) recommended using probabilistic methods for the assessment of masonry strength to facilitate the description of:

- Randomness of material characteristics of masonry units and mortar;

- Statistical uncertainties due to a limited number of tests;

- Inaccuracies of testing methods;

- Simplifications in the model for masonry strength (model uncertainty).

The obtained experimental results are further applied in the probabilistic assessment of masonry strength. It is based on the procedure for the assessment of compressive strength of masonry in the direction perpendicular 
to bed joints pursuant to EN 1996-1-1:2005 (2005) for design of masonry structures and the Czech National Annex to ISO 13822:2010 (2010) for the assessment of existing structures. The design values obtained by the deterministic approach are compared to the corresponding fractiles of a probabilistic model.

\section{Model of compressive masonry strength}

\subsection{Deterministic approach}

In accordance with EN 199611:2005 (2005) and the Czech National Annex to ISO 13822:2010 (2010), the characteristic compressive strength $f_{\mathrm{k}}$ of non-reinforced masonry made with general purpose mortar is obtained as follows:

$$
f_{\mathrm{k}}=K_{\mathrm{nom}} f_{\mathrm{b}}^{\alpha} f_{\mathrm{m}}^{\beta}
$$

where: $K_{\text {nom }}$ denotes the coefficient for the calculation of compressive strength of masonry (nominal value); $f_{\mathrm{b}}$ the standardised strength of masonry units; $f_{\mathrm{m}}$ the strength of mortar; and $\alpha$ and $\beta$ are constants (regression coefficients). The empirical Eqn (4) need not always describe the actual compressive strength of masonry with adequate accuracy. In some cases, other models may be more suitable, such as the exponential function similar to Eqn (4) with general values of exponents (JCSS 2011) or more advanced methods described by Stewart and Lawrence (2002).

While assessing existing structures, the standardised strength of masonry units is evaluated on the basis of strengths obtained from destructive and non-destructive tests $\left(f_{\mathrm{b}, \text { test }}\right)$ using the conversion factor $\eta_{\mathrm{b}}$ :

$$
\eta_{\mathrm{b}}=f_{\mathrm{b}} / f_{\mathrm{b}, \text { test }} .
$$

The mean value of $f_{\mathrm{b}}$, which is substituted in Eqn (4), is obtained as the product of the mean values from the tests and the conversion factor:

$$
\mu_{f \mathrm{~b}} \approx \mu_{\eta \mathrm{b}} \mu_{f b, \mathrm{test}} .
$$

The conversion factor $\eta_{m}$ for mortar strength, evaluated on the basis of non-destructive or minor-destructive tests $\left(f_{\mathrm{m}, \text { test }}\right)$ is defined in a similar way; and thus:

$$
\mu_{\mathrm{fm}} \approx \mu_{\eta \mathrm{m}} \mu_{\mathrm{fm}, \mathrm{est}} .
$$

Hence, Eqn (4) can be rewritten as:

$$
f_{\mathrm{k}}=K_{\text {nom }}\left(\mu_{\eta \mathrm{b}} \mu_{f \mathrm{~b}, \text { test }}\right)^{\alpha}\left(\mu_{\eta \mathrm{m}} \mu_{\text {fm,test }}\right)^{\beta} .
$$

The design value of masonry strength is derived from the characteristic value by introducing the partial factor $\gamma_{\mathrm{M}}$ :

$$
f_{\mathrm{d}}=f_{\mathrm{k}} / \gamma_{\mathrm{M}}
$$

In accordance with the Czech National Annex to ISO 13822:2010 (2010), the partial factor is the product of the following four partial factors:

$-\gamma_{\mathrm{m} 1}$ - the basic value of the partial factor;

$-0.85 \leq \gamma_{\mathrm{m} 2} \leq 1.2$ - the coefficient considering the effect of the regularity of the masonry bond and the filling of joints with mortar; the lower bound applies to a regular bond and perfect filling of joints with mortar;

$-1.0 \leq \gamma_{\mathrm{m} 3} \leq 1.25$ - the coefficient considering the effect of increased moisture, for moisture between $4 \%$ to $20 \%$ linear interpolation is used,

$-1.0 \leq \gamma_{\mathrm{m} 4} \leq 1.4$ - the coefficient considering the effect of vertical and inclined cracks in masonry.

\subsection{Probabilistic approach}

To enhance the accuracy of estimates of the characteristic and design value, a probabilistic model of masonry strength based on Eqn (8) is proposed. Apart from the coefficients $\alpha$ and $\beta$, all variables are considered as random. Ellingwood and Tallin (1985), Stewart and Lawrence (2007), Mojsilovic and Faber (2009) pointed out that the strengths $f_{\mathrm{b}}$,test and $f_{\mathrm{m} \text { test }}$ can be described by a lognormal distribution; this distribution is also adopted here for the conversion factors $\eta_{\mathrm{b}}$ and $\eta_{\mathrm{m}}$. These assumptions are reasonable in the majority of cases. The resultant masonry strength is then also lognormal. The logarithm $\ln (f)$ has a normal distribution with the mean and the standard deviation:

$$
\begin{gathered}
\mu_{\ln (f)}=\mu_{\ln (K)}+\alpha\left[\mu_{\ln (\eta \mathrm{b})}+\right. \\
\left.\mu_{\ln (f \mathrm{~b}, \text { test })}\right]+\beta\left[\mu_{\ln (\eta \mathrm{m})}+\mu_{\ln (f \mathrm{~m}, \text { test })}\right] ; \\
\sigma_{\ln (f)}=\sqrt{\left\{\sigma_{\ln (K)}{ }^{2}+\alpha^{2}\left[\sigma_{\ln (\eta \mathrm{b})^{2}}+\sigma_{\ln (f \mathrm{~b}, \text { test })}\right]+\right.} \\
\left.\beta^{2}\left[\sigma_{\ln (\eta \mathrm{m})}{ }^{2}+\sigma_{\ln (f \mathrm{~m}, \text { test })}{ }^{2}\right]\right\},
\end{gathered}
$$

where: $\mu_{\ln (X)}$ and $\sigma_{\ln (X)}$ refer to the mean and the standard deviation of $\ln (X)$ :

$\mu_{\ln }(X)=\ln \left(\mu_{X}\right)-0.5 \ln \left[1+V_{X}^{2}\right] ; \sigma_{\ln }(X)=\sqrt{ }\left\{\ln \left[1+V_{X}^{2}\right]\right\}$,

where: $\mu_{X}$ and $V_{X}=\sigma_{X} / \mu_{X}$ denote the mean and the coefficient of variation of the variable $X$. The strength characteristics of masonry, therefore, may be assessed by analytical relationships.

Characteristic and design values are usually defined as a fractile of the probability distribution of a material property. The fractile of a lognormal distribution $x_{p}$ is obtained as follows:

$$
x_{p}=\mu_{X} \times \exp \left\{u_{p} \sqrt{ }\left[\ln \left(1+V_{X}^{2}\right)\right]\right\} / \sqrt{ }\left(1+V_{X}^{2}\right),
$$

where: $u_{p}=\Phi^{-1}(p)$ is the fractile of a standardised normal distribution of a corresponding probability $p$, obtained from the inverse distribution function of the standardised normal distribution $\Phi^{-1}$ available in numerous software products. Thus, the fractile calculation is simple and does not require specialised software.

In accordance with EN 1990:2002 (2002) for the basis of structural design, the characteristic value cor- 
responds to a 5\% fractile, while the design value of a material property is a fractile of the corresponding probability $p_{\mathrm{d}}$ :

$$
p_{\mathrm{d}}=\Phi\left(-\alpha_{R} \times \beta_{t}\right)=\Phi(-0.8 \times 3.8)=0.0012,
$$

where $\Phi(\cdot)$ is the distribution function of a standardised normal distribution, the sensitivity coefficient of the FORM method $\alpha_{R} \approx 0.8$ (EN 1990:2002 (2002)), and the target reliability index $\beta_{t}=3.8$ applies for a fifty-year reference period. It is assumed that the partial factor $\gamma_{M}$ is based on these values.

ISO 13822:2010 (2010) states that target reliability levels lower (than those applied in structural design) may be used for existing structures, if justified on the basis of socioeconomic aspects. For common existing structures, moderate costs of safety measures may be considered together with moderate consequences of a failure. In this case, ISO 2394:1998 (1998) indicates $\beta_{t}=3.1$.

In the case of a historic structure, we may expect:

- high costs of safety measures (considering potential losses of the heritage value due to rehabilitation, or more costly technologies of rehabilitations), but also

- high failure consequences including a loss of the heritage value.

Even in this case, however, ISO 2394:1998 indicates $\beta_{\mathrm{t}}=3.1$. Considering this value, the probability corresponding to the design value $f_{\mathrm{d}}$ is:

$$
p_{\mathrm{d}}=\Phi(-0.8 \times 3.1)=0.0066 .
$$

For more detailed information on the assessment of appropriate target reliability levels (see, e.g. Schueremans, Van Gemert 2004; Vrouwenvelder, Scholten 2010; Sykora, Holicky 2012).

\section{Probabilistic models of basic variables}

The proposed probabilistic model is further used in the assessment of the strength of mixed masonry of a church from the $17^{\text {th }}$ century. Statistical characteristics of the variables affecting masonry strength are summarised in Table 2; a lognormal distribution is considered for all the variables. For simplification, statistical uncertainties related to a limited number of tests are not considered in the probabilistic analysis. In a more detailed analysis, however, it would be desirable to consider the uncertainties in the identification of the mean and the standard deviation of $f_{\mathrm{b} \text {,est }}$ and $f_{\mathrm{m} \text {,est }}$.

The probabilistic models of conversion factors are based on the following assumptions:

- $\eta_{\mathrm{b}}$ - tests in a press on small specimens may include a measurement error assumed unbiased $\left(\mu_{\eta \mathrm{b}}=1\right)$; based on long-term experience (Sykora, Holicky 2010; JCSS 2011) the coefficient of variation is $V_{\eta \mathrm{b}}=0.2$.

- $\eta_{\mathrm{m}}$ - based on experience available the conversion factor for tests with the drill with an indenter is described by statistical characteristics $\mu_{\eta \mathrm{m}}=1$ and $V_{\eta \mathrm{m}}=0.2$.
To calculate the characteristic strengths of nonreinforced masonry in accordance with the Czech National Annex NF to ISO 13822:2010 (2010), the coefficient $K$ must be determined. According to EN 199611:2005 (2005), $K_{\text {nom }}=0.5$ is considered (group of masonry units 2a). Unlike the strength of masonry units and mortar, it is normally necessary to establish the probabilistic model for $K$ on the basis of previous experience and experimental data in available literature (Sykora, Holicky 2010; JCSS 2011; Brehm 2011). The probabilistic model describes model uncertainties covering the lack of experimental data, the model simplification and the effect of the unknown workmanship quality. It might be assumed that $\mu_{K} / K_{\text {nom }}=1.25$ and $V_{K}=0.2$; a lognormal distribution is an appropriate probabilistic model.

\subsection{Deterministic analysis}

The characteristic strength $f_{\mathrm{k}}$ of non-reinforced masonry in compression made of general purpose mortar is obtained from Eqn (8):

$$
\text { Alt. A: } \mu f_{\mathrm{k}}=0.5 \times(1 \times 7.7)^{0.65} \times(1 \times 1.44)^{0.25}=
$$$$
2.1 \mathrm{MPa} ; B: \mu f_{\mathrm{k}}=0.5 \times(1 \times 23.9)^{0.65} \times(1 \times 1.44)^{0.25}=
$$

$$
4.3 \mathrm{MPa} \text {, }
$$

where: $\alpha=0.65$ and $\beta=0.25$ for non-reinforced masonry with general purpose mortar in accordance with the Czech National Annex to ISO 13822:2010 (2010). It appears that the strength of mixed masonry is twice higher than based on the material with lower strength. That is why the decision whether the characteristics of mixed masonry can be considered is of uttermost importance in the assessment.

Statistical uncertainties resulting from a limited amount of data are not considered in Eqn (15). Considering the lower bounds of the interval estimates in (2) and (3), we obtain $f_{\mathrm{k}(\mathrm{A})}=1.7 \mathrm{MPa}$ and $f_{\mathrm{k}(\mathrm{B})}=3.8 \mathrm{MPa}$, i.e. values by $10-20 \%$ lower. It thus seems desirable to account for statistical uncertainty in this case. To provide a general indication the effect of statistical uncertainty is greater than $10 \%$ and should be taken into account for sample sizes of masonry unit strengths lower than 15. The statistical uncertainty related to sample sizes of mortar strengths is commonly less significant and can be neglected.

The design value of masonry strength is derived from the characteristic value by means of the partial factor $\gamma_{\mathrm{M}}=2.86$ obtained as the product of the following partial factors:

$-\gamma_{\mathrm{m} 1}=2.0$ for masonry of full bricks laid on general purpose mortar;

$-\gamma_{\mathrm{m} 2}=1.2$ (the effect of the regularity of the brick bond and filling of joints with mortar);

$-\gamma_{\mathrm{m} 3}=1.19$ (increased moisture);

$-\gamma_{\mathrm{m} 4}=1.0$ (no degradation and no cracks).

The design values for the lower bounds on $\mu_{f b}$,test and $\mu_{\text {fim test }}$ are obtained from Eqn (9): 
Alt. A: $f_{\mathrm{d}}=1.7 / 2.86=0.60 \mathrm{MPa}$;

Alt. B: $f_{\mathrm{d}}=3.8 / 2.86=1.33 \mathrm{MPa}$.

\subsection{Probabilistic analysis}

The proposed probabilistic model for masonry strength (Eqns (10) to (12)) leads to:

$\begin{array}{lll}\text { Alt. A: } \mu_{f}=2.52 \mathrm{MPa} ; & V_{f}=0.34 ; & f_{\mathrm{d}}=1.1 \mathrm{MPa} ; \\ \text { Alt. B: } \mu_{f}=5.17 \mathrm{MPa} ; & V_{f}=0.44 ; & f_{\mathrm{d}}=1.7 \mathrm{MPa}\end{array}$

The probability density function of masonry strength and design values are shown in Figure 11 (black - Alt. A, grey - Alt. B). Table 3 presents the characteristic and design values of masonry strength for the deterministic and probabilistic approach and partial factors (obtained as the characteristic/design value ratio in the probabilistic approach). It appears that:

- The characteristic value obtained as a $5 \%$ fractile is by $20-35 \%$ lower than the characteristic value in accordance with ISO 13822:2010 (2010), which rather corresponds to the mean value.

- The design value for Alt. A and $\beta_{\mathrm{t}}=3.1$, based on the probabilistic approach, is by $75 \%$ higher than that obtained by the deterministic approach.

- In Alt. B the differences between the design values are less significant (25\%) since the combination of

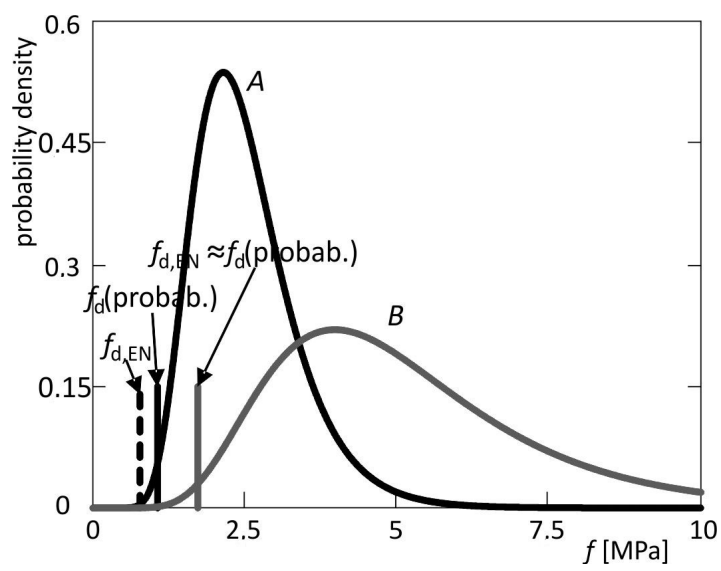

Fig. 11. The probability density function of masonry strength and design values

Table 3. Characteristic and design values of masonry strength (in $\mathrm{MPa}$ ) and partial factors

\begin{tabular}{lccc}
\hline \multicolumn{1}{c}{ Alternative } & Variable & Deterministic & Probabilistic \\
\hline$A$ (only bricks) & $f \mathrm{k}$ & $1.71^{*}$ & $1.39^{* *}$ \\
\hline & $f \mathrm{~d}$ & $0.60^{*}$ & $1.06^{* * *}$ \\
\hline $\begin{array}{l}\text { B (bricks }+ \\
\text { sandstone) }\end{array}$ & $f \mathrm{k}$ & 2.86 & 1.32 \\
\hline & $f \mathrm{~d}$ & $1.79^{*}$ & $2.38^{* *}$ \\
\hline & $\gamma \mathrm{M}$ & 2.86 & $1.68^{* * *}$ \\
\hline
\end{tabular}

${ }^{*}$ Considering statistical uncertainty in the identification of mean values of $f_{\mathrm{b}, \text { test }}$ and $f_{\mathrm{m} \text {, test }} ;{ }^{* *} 5 \%$ fractile; ${ }^{* * *} \beta_{\mathrm{t}}=3.1$. materials leads to a higher coefficient of variation of masonry units, which decreases the probabilistic design value.

- The partial factor for the deterministic approach is significantly higher due to the differences between the characteristic value and the $5 \%$ fractile and due to an imperfect (general) description of the uncertainties related to the identification methods of material properties.

Based on the reported results and also previous experience, the probabilistic approach seems to lead to similar or higher design values of masonry strength than the deterministic approach.

\section{Discussion and recommendations}

The experimental part of the study focusing on general aspects of the assessment of the strength of historic mixed masonry, the sampling of specimens of masonry units and mortar and the assessment of tests yields the following recommendations:

- in masonry containing chippings and sharp-edged walling units of freestone, the positive effect of the tri-axial stress state of mortar cannot be considered;

- differences in the stiffness of individual masonry units of mixed masonry may significantly affect principal stresses - local stress states characterised by the tensile component arise in the vicinity of masonry units with a relatively higher modulus of elasticity against the surrounding units, and they may be unfavourably manifested in stone or mixed masonry only at higher values;

- inaccuracy in the identification of physical and mechanical properties of historic masonry (mainly when using non-destructive methods) must be taken into account in the specification of residual design values of these properties;

- inaccuracies in the identification of boundary conditions and physical and mechanical properties of masonry and its components cannot be eliminated even if advanced numerical methods are applied;

- due to the variability of masonry properties, information about its mechanical properties must be obtained by testing; the evaluation of masonry strength may then have a key role in the assessment of residual properties of historic and other existing structures;

- outlying observations, which may be caused by a measurement error or by measurement at a spot of local non-homogeneity, must be verified; such observations may distort the sample characteristics of the data set and lead to erroneous conclusions;

- the assessment of material properties on the basis of tests requires special care; non-destructive procedures must usually be complemented by destructive tests. 


\section{Conclusions}

The assessment of residual ultimate strength/loading capacity of masonry in compression using destructive or non-destructive tests must take into account uncertainties in the determination of physical and mechanical characteristics of historic mixed masonry, its composition, integrity (the extent of masonry degradation by cracks), masonry workmanship quality (masonry bond), or the degree of masonry degradation. A growing uncertainty in the description of the masonry condition and the properties of its individual components must be accompanied by a growing ratio of experimentally identified ultimate strength and admissible loading of the masonry. The basis for the assessment of residual ultimate load-bearing capacity of masonry in compression should be destructive tests of sampled test cores. The assessment of the residual load-bearing capacity of masonry composed of irregular walling units (of freestone), of different types of natural stone and of multi-layer masonry requires special care. An inseparable part of the identification of residual load-bearing capacity of masonry is a detailed description, mapping and analysis of all mechanical defects, cracks, the condition of surface layers, masonry heterogeneity, the thickness and quality of binder in bed joints, the type and dimensions of walling units and the masonry bond. Any reconstruction project should always respect the principle of the preservation of the original structural concept and design of the whole structure, or potential removal of all former insensitive interventions and heterogeneous structural members. Erroneous conclusions and a wrong rehabilitation concept may be caused by the use of either sophisticated mathematical models or insufficiently accurate material and physical models.

As compared to deterministic methods, the probabilistic approach allows a better description of the inherent randomness of basic variables, statistical uncertainties, inaccuracies of testing methods and model uncertainties; therefore, this method leads to less conservative results in most cases. The presented probabilistic approach is suitable for practical applications as no specialised software is needed. The case study is focused on a church from the $17^{\text {th }}$ century; the assessment of the compressive strength of mixed masonry reveals that the design value calculated by the probabilistic method is by about $75 \%$ higher as compared to the deterministic approach. Considerable heterogeneity of mixed masonry, the variability of the properties and irregularities of masonry units and masonry bonds require exceptional care in the selection and interpretation of the results of experimental methods to identify the strength of masonry components and in the subsequent identification of residual load-bearing capacity of mixed masonry.

\section{Acknowledgements}

The article was written with support from the NAKI DF12P01OVV037 project "Progressive non-invasive methods of the stabilisation, conservation and strengthening of historic structures and their parts with composite materials based on nanofibres" supported by the Ministry of Culture of the Czech Republic.

\section{References}

Ang, A. H. S.; Tang, W. H. 2007. Probabilistic concepts in engineering emphasis on applications to civil and environmental engineering. $2^{\text {nd }}$ ed. New York: John Wiley \& Sons. 420 p.

Brehm, E. 2011. Reliability of unreinforced masonry bracing walls. TU Darmstadt. 207 p.

Ellingwood, B. R.; Tallin, A. 1985. Limit states criteria for masonry construction, Journal of Structural Engineering ASCE 111(4): 108-122.

http://dx.doi.org/10.1061/(ASCE)0733-9445(1985)111:1(108)

EN 1990:2002 Basis of structural design. European Committee for Standardization, 2002.

EN 1996-1-1 2005 Design of masonry structures - Part 1-1: General rules for reinforced and unreinforced masonry structures. European Committee for Standardization, 2005.

Grubbs, F. 1969. Procedures for detecting outlying observations in samples, Technometrics 11(1): 1-21. http://dx.doi.org/10.1080/00401706.1969.10490657

Holický, M. 2013. Introduction to probability and statistics for engineers. Berlin Heidelberg: Springer. $181 \mathrm{p}$. http://dx.doi.org/10.1007/978-3-642-38300-7

Holický, M.; Hrabánek, M.; Kolísko, J.; Sýkora, M. 2009. Assessment of Masonry Strength in a Heritage Building, in Proc. STREMAH XI, 22-24 July 2009, Tallin, Estonia, $185-195$.

ISO 138222010 Bases for design of structures - Assessment of existing structures. International Organization for Standardization, 2010.

ISO 23941998 General principles on reliability for structures. International Organization for Standardization, 1998.

JCSS. 2011. JCSS Probabilistic Model Code. Joint Committee on Structural Safety, 2011.

Kotlík, P., et al. 1999. Building materials of historic buildings materials, corrosion, maintenance. VŠCHT Publishing (in Czech).

Mojsilovic, N.; Faber, M. H. 2009. Probabilistic assessment of masonry compressive strength, in Proc. of ICOSSAR 2009, 13-17 September 2009, Osaka, Japan, 3609-3613.

Schueremans, L.; Van Gemert, D. 2004. Assessing the safety of existing structures: reliability based assessment framework, examples and application, Journal of Civil Engineering and Management (5): 131-141.

Stewart, M. G.; Lawrence, S. 2002. Structural reliability of masonry walls in flexure, Masonry International 15(5): 48-52.

Stewart, M. G.; Lawrence, S. J. 2007. Model error, structural reliability and partial safety factors for structural masonry in compression, Masonry International 20(6): 107-116.

Sykora, M.; Holicky, M. 2012. Target reliability levels for the assessment of existing structures - case study, in Proc. of IALCCE 2012, 3-6 October 2012, Vienna, Austria, 813-820.

Sykora, M.; Holicky, M. 2010. Probabilistic model for masonry strength of existing structures, Engineering Mechanics 174(4): 61-70.

Šatava, V. 1973. Relation between pore structure and mechanical properties of materials, in International Conference of Pore Structure and Properties of Materials, 18-21 September 1973, Prague, Czech Republic, D-5-D-25.

Vrouwenvelder, A. C. W. M.; Scholten, N. 2010. Assessment criteria for existing structures, Structural Engineering 
International 20(4): 62-65. http://dx.doi.org/10.2749/101686610791555595

Winkler, E. M. 1975. Stone: properties, durability in man's environment. $2^{\text {nd }}$ ed. Vienna, New York: Springer Verlag. 230 p. http://dx.doi.org/10.1007/978-3-7091-3819-9

Witzany, J.; Čejka, T.; Zigler, R. 2006. The analysis of nonstress effects on historical stone bridge structures (monitoring, theoretical analysis, maintenance), in Proc. of EASEC-10, 2006, vol. 6, Bangkok, Asian Institute of Technology, 21-26.
Witzany, J.; Čejka, T.; Zigler, R. 2008.Failure resistance of the historic stone bridge structure of Charles Bridge. I: susceptibility to nonstress effects, Journal of Performance of Constructed Facilities 22(2): 71-82.

Witzany, J.; Čejka, T.; Zigler, R. 2009. Analysis of the residual resistance of historic masonry structures, in $31^{\text {st }}$ Conference (11. conference WTA CZ) Rehabilitation and Reconstruction of Buildings, 3-4 November 2009, Prague, Czech Republic (in Czech).

Jiří WITZANY. Professor, DrSc, Dr h.c., Eng., Rector Emeritus, Dean FCE CTU 1990-1996, Rector CTU 2000-2006, Department of Building Structures (Head of the Department 1990-2008), Faculty of Civil Engineering, Czech Technical University in Prague, Czech Republic. Professional activities during last 10 years: Chief researcher of 2 research plan and 10 grant, author and co-author of 10 monographs, 10 utility designs, 5 patents, 58 scientific and professional articles and over 80 papers on national and international conferences, 25 research reports. He devoted himself to structural problems of designing building structures, has carried out extensive theoretic and experimental research of prefabricated and masonry structures, reconstruction and rehabilitation designs of concrete and masonry buildings, strengthened of masonry structures by CFRP and GFRP, degradation processes, durability and reliability of buildings. He has designed the reconstruction concept of the midlle age Charles Bridge in Prague.

Tomáš ČEJKA. Assoc. Professor, PhD, Eng. at the Department of Bulding Constructions, Faculty of Civil Engineering, Czech Technical University in Prague, Czech Republic. Professional activities during last 10 years: Co-researcher of 2 research plan and 10 grant, co-author of 8 monographs, 10 utility designs, 38 scientific and technical articles and over 48 papers on national and international conferences, 18 research reports. His research interests include structural analysis, mainly of masonry and precast concrete structures, reconstructions and renovations of buildings, etc.

Miroslav SÝKORA. Eng., PhD, Czech Technical University in Prague, Klokner Institute. His research interests include basis of structural design, structural reliability, probabilistic optimisation, load modelling, risk assessment of technical systems and applications of probabilistic methods in structural design. He is an author or co-author of several handbooks for practising engineers and a number of scientific publications (more than 100, most of them in English). He is a member of the Joint Committee on Structural Safety, fib (Activity Group 7 Assessment and Interventions upon Existing Structures) and the Czech national contact for the Horizontal Group - Bridges of CEN.

Milan HOLICKÝ. Prof., Eng., PhD, DrSc, Czech Technical University in Prague, Klokner Institute. He is involved in the research of structural reliability and risk assessment. He is the author or co-author of more than 300 scientific and technical publications, including textbooks and five monographs. Since 1991, he has represented the Czech Republic on the European Committee for Standardisation (CEN) as a member of the Technical committee TC 250 "Structural Eurocodes". In 2010 he became Extraordinary Professor at the University of Stellenbosch, South Africa; in 2011 he was awarded the Honorary Doctor of Science and Engineering degree from Moscow State University of Civil Engineering. 